Check for updates

Cite this: Chem. Sci., 2019, 10, 3065

๑ All publication charges for this article have been paid for by the Royal Society of Chemistry

Received 5th November 2018

Accepted 23rd January 2019

DOI: $10.1039 / c 8 s c 04917 c$

rsc.li/chemical-science

\section{Molecular multifunctionality preservation upon surface deposition for a chiral single-molecule magnet $\uparrow$}

\author{
Dmitri Mitcov, (D) ${ }^{a}$ Anders H. Pedersen, ${ }^{a}$ Marcel Ceccato, ${ }^{a}$ Rikke M. Gelardi, ${ }^{a}$ \\ Tue Hassenkam, ${ }^{a}$ Andreas Konstantatos, (D) ${ }^{a}$ Anders Reinholdt, (D) ${ }^{a}$ \\ Mikkel A. Sørensen, ${ }^{a}$ Peter W. Thulstrup, (D) ${ }^{a}$ Morten G. Vinum, (DD a Fabrice Wilhelm, ${ }^{b}$

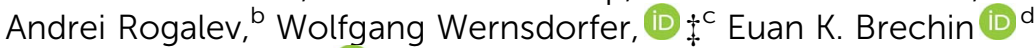 \\ and Stergios Piligkos (D) *a
}

\begin{abstract}
The synthesis and characterization of a chiral, enneanuclear $\mathrm{Mn}(\mathrm{III})$-based, Single-Molecule Magnet, $\left[\mathrm{Mn}_{9} \mathrm{O}_{4}(\mathrm{Me}-\mathrm{sao})_{6}(\mathrm{~L})_{3}(\mathrm{MeO})_{3}(\mathrm{MeOH})_{3}\right] \mathrm{Cl}\left(1 ; \mathrm{Me}-\mathrm{saoH}_{2}=\right.$ methylsalicylaldoxime, $\mathrm{HL}=$ lipoic acid $)$ is reported. Compound 1 crystallizes in the orthorhombic $P 2_{1} 2_{1} 2_{1}$ space group and consists of a metallic skeleton describing a defect super-tetrahedron missing one vertex. The chirality of the $\left[\mathrm{Mn}^{\mathrm{II}}{ }_{9}\right]$ core originates from the directional bridging of the $\mathrm{Me}-\mathrm{sao}^{2-}$ ligands via the $-\mathrm{N}-\mathrm{O}$ - oximate moieties, which define a clockwise $(\mathbf{1 \Delta \Delta})$ or counter-clockwise $(1 \mathbf{\Lambda} \Lambda)$ rotation in both the upper $\left[\mathrm{Mn}^{\prime \prime \prime}{ }_{3}\right]$ and lower $\left[\mathrm{Mn}^{\prime \prime \prime}{ }_{6}\right]$ subunits. Structural integrity and retention of chirality upon dissolution and upon deposition on

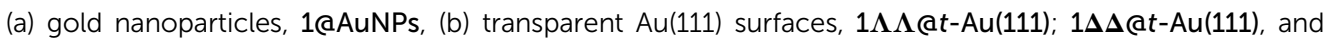
(c) epitaxial $\mathrm{Au}(111)$ on mica surfaces, 1(ee-Au(111), was confirmed by CD and IR spectroscopies, mass spectrometry, TEM, XPS, XAS, and AFM. Magnetic susceptibility and magnetization measurements demonstrate the simultaneous retention of SMM behaviour and optical activity, from the solid state, via dissolution, to the surface deposited species.
\end{abstract}

\section{Introduction}

Modern information technology is based on the combined use of the charge and spin properties of electrons, exploited within devices incorporating magnetic nanomaterials. ${ }^{1,2}$ The next generation of such devices will incorporate molecular magnetic materials that serve the purpose of miniaturization and allow the exploitation of the quantum properties that matter exhibits at this scale. ${ }^{3}$ The controlled deposition of such materials on substrates $^{4-7}$ and the subsequent addressing and manipulation of their magnetic moment at the molecular level ${ }^{8-10}$ is

\footnotetext{
${ }^{a}$ Department of Chemistry, University of Copenhagen, Universitetsparken 5, DK-2100, Copenhagen, Denmark.E-mail: piligkos@chem.ku.dk

${ }^{b}$ ESRF-The European Synchrotron, CS 40220, 38043 Grenoble Cedex 9, France 'Institute Néel, CNRS, BP 166, 25 Avenue de Martyrs, Grenoble, 38042 Cedex 9, France ${ }^{d}$ EaStCHEM School of Chemistry, The University of Edinburgh, David Brewster Road, Edinburgh, EH9 3FJ, UK

$\dagger$ Electronic supplementary information (ESI) available: Full experimental details and additional data for all the characterizations presented in the main text. Crystallographic data (including structure factors) for $\mathbf{1 \Delta \Delta}$ and $\mathbf{1} \mathbf{\Lambda} \mathbf{\Lambda}$ have been deposited with the Cambridge Crystallographic Data Centre (CCDC 1839660-1839661, respectively). For ESI and crystallographic data in CIF or other electronic format see DOI: 10.1039/c8sc04917c
}

* Present Address: Institute of Nanotechnology, Karlsruhe Institut für Technologie, 76344 Eggenstein-Leopoldshafen, Germany. a prerequisite for device realization. This can be achieved through the use of chiral magnetic molecular materials, since the absence of an inversion centre leads to efficient coupling of electric fields to the molecular magnetic moment, ${ }^{11}$ and to magnetochirality, ${ }^{12-14}$ a second order non-reciprocal effect that can be harnessed by unpolarised light. ${ }^{14}$ Thus, surface deposited chiral magnetic molecular materials are excellent candidates for the realization of spintronic devices operating on the basis of electric or optical control of molecular magnetic moments via spin-electric coupling or the magnetochiral effect. Single-Molecule Magnets ${ }^{15,16}$ (SMMs) are a class of molecular materials currently considered for applications in molecular spintronics, such as quantum computing. ${ }^{17-19}$ The unique potential of SMMs lies in their physics dominated by quantum effects such as quantum tunnelling of the magnetisation, ${ }^{20}$ Berry phase ${ }^{21}$ and spin coherence. ${ }^{22}$ However, there still persists a crucial open question: how are the molecular properties affected by the drastic change in molecular environment that occurs upon surface deposition?

Until very recently, the few studies that addressed the spin dynamics of SMMs deposited on metallic surfaces showed serious alteration of the molecular properties after deposition on the surface and failed to observe magnetic hysteresis. It has been shown that $\mathrm{Mn}_{12}$ is reduced when deposited at monolayer level on gold. ${ }^{23}$ It has also been shown by several recent studies 
that the molecular magnetic properties of SMMs evolve upon dissolution $^{\mathbf{2 4 2 5}}$ or deposition on surfaces. ${ }^{26}$ It is only very recently that magnetic hysteresis from a tetranuclear $\mathrm{Fe}(\mathrm{III})$ SMM anchored on a gold surface by thiolate groups, ${ }^{27-29}$ or on carbon-nanotubes (CNTs), ${ }^{30}$ from $\mathrm{Mn}_{12}$ on $\mathrm{Au}(111),{ }^{28}$ and from Ln-based SMMs anchored on CNTs, ${ }^{31}$ on gold, ${ }^{32}$ on magnesium oxide, ${ }^{33}$ or on silicon, ${ }^{34}$ was detected. The grafting of $\mathrm{Cr}_{7} \mathrm{Ni}$ on gold and on highly oriented pyrolytic graphite was also reported. ${ }^{35,36}$ Very recently, engineering of the magnetic coupling and anisotropy of a Co ${ }^{\mathrm{II}}$ - and of a $\mathrm{Ni}^{\mathrm{II}}$-based SMM with the $\mathrm{Fe}_{3} \mathrm{O}_{4}$

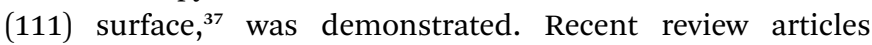
present the main strategies for the attachment of SMMs on surfaces. ${ }^{4-6}$ Chiral SMMs have been extensively studied in the bulk $^{38}$ but to the best of our knowledge simultaneous retention of chirality and SMM behaviour has never been demonstrated upon surface deposition.

Herein, we present the synthesis and characterization of a chiral, enneanuclear $\mathrm{Mn}(\mathrm{III})$-based $\mathrm{SMM},\left[\mathrm{Mn}_{9} \mathrm{O}_{4}(\mathrm{Me}-\mathrm{sao})_{6}(\mathrm{~L})_{3}\right.$ $\left.(\mathrm{MeO})_{3}(\mathrm{MeOH})_{3}\right] \mathrm{Cl}(\mathbf{1})$, where $\mathrm{LH}$ is lipoic acid and $\mathrm{Me}-\mathrm{SaOH}_{2}$ is methylsalicylaldoxime, functionalized for surface deposition and stable in solution. We demonstrate, for the first time, the simultaneous retention of superparamagnetism-like SMM behaviour and chirality, from the solid state, via dissolution, to the surface deposited species.

\section{Results and discussion}

\section{Solid state}

1 (Fig. 1a and S1a $\dagger$ ) crystallizes in the orthorhombic $P 2_{1} 2_{1} 2_{1}$ space group (Table S1†) which is one of the 65 Sohncke space groups that contain only symmetry operations of the first kind (rotations and translations) and can accommodate chiral molecules. ${ }^{39}$ Only species of the same enantiomeric structure are present in a given crystal of 1 . The chirality of the $\left[\mathrm{Mn}^{\mathrm{III}}{ }_{9}\right]$ core in 1 originates from the directional bridging of the $\mathrm{Me}$ $\mathrm{sao}^{2-}$ ligands via the $-\mathrm{N}-\mathrm{O}-$ oximate moieties, which define a clockwise $(\mathbf{1} \boldsymbol{\Delta} \boldsymbol{\Delta})$ or counter-clockwise $(\mathbf{1} \Lambda \mathbf{\Lambda})$ rotation in both the upper $\left[\mathrm{Mn}_{3}{ }_{3}\right]$ and lower $\left[\mathrm{Mn}_{6}^{\mathrm{III}}\right]$ subunits (Fig. 1b), with respect to the axis normal to both planes. The metal-core of $\mathbf{1}$ consists of nine $\mathrm{Mn}$ (III) ions describing a defect supertetrahedron missing one vertex (Fig. 1a). In the upper $\left[\mathrm{Mn}_{3}^{\mathrm{III}}\right]$ subunit, the three $\mathrm{Mn}$ (III) ions are linked by a central $\mu_{3}-\mathrm{O}^{2-}$ ion, while the edges of the $\left[\mathrm{Mn}_{3}{ }_{3}\right]$ triangle consist of three bridging -N-O- oximates ( $\mathrm{Mn}-\mathrm{N}-\mathrm{O}-\mathrm{Mn}$ torsion angles: 38.0-39.5 ${ }^{\circ}$, Tables S2 and S3 $\dagger$ ) from the Me-sao ${ }^{2-}$ ligands. The upper face of the $\left[\mathrm{Mn}_{3}{ }_{3}^{\mathrm{II}}\right]$ unit is capped by three $\mathrm{MeOH}$ molecules (Mn$\mathrm{O}_{\mathrm{MeOH}}=2.180-2.206 \AA$ Tables $\mathrm{S} 4$ and $\left.\mathrm{S} 5 \dagger\right)$ and the counteranion $\left(\mathrm{Cl}^{-}\right)$that is $\mathrm{H}$-bonded to the capping solvent $\left(\mathrm{H}_{\mathrm{MeOH}} \cdots\right.$ $\mathrm{Cl}^{-}$2.190-2.200 ̊). In the basal [ $\mathrm{Mn}_{6}{ }_{6}^{\mathrm{II}}$ ] subunit, the almost coplanar $\mathrm{Mn}$ (III) ions are alternately connected from the exterior by three oximates ( $\mathrm{Mn}-\mathrm{N}-\mathrm{O}-\mathrm{Mn}$ torsion angles: 8.6-13.7 ${ }^{\circ}$, Tables S2 and $\mathrm{S} 3 \dagger)$ and three methoxides $\left(\mathrm{Mn}-\mathrm{O}_{\mu-\mathrm{MeO}}-\mathrm{Mn}\right.$ angles: $98.79-100.16^{\circ}$, Tables S6 and S7†), while from the interior the metal-ions are linked via three $\mu_{4}-\mathrm{O}^{2-}$ bridges. Thus, the six Mn(III) ions form a triangle with three ions positioned at the vertices and the other three at the middle of the edges. The lower face of the $\left[\mathrm{Mn}^{\mathrm{III}}{ }_{6}\right]$ subunit is capped by three sulfur-containing carboxylates, bonding in a bidentate bridging fashion conferring tripodal ligand attributes to 1 . The inner $\mu_{4^{-}}$ $\mathrm{O}^{2-}$ ion from the basal $\left[\mathrm{Mn}^{\mathrm{III}}{ }_{6}\right]$ unit, the oximato $\mathrm{O}$-atoms from the bridging aldoximes, the phenoxide O-atoms of $\mathrm{Me}^{-\mathrm{SaO}^{2-}}$ and the $-\mathrm{N}-\mathrm{O}$ - oximate bridges from the upper $\left[\mathrm{Mn}_{3}{ }_{3}^{\mathrm{II}}\right]$ subunit link $\left[\mathrm{Mn}_{3}^{\mathrm{III}}\right]$ and $\left[\mathrm{Mn}_{6}^{\mathrm{III}}{ }_{6}\right]$ to form the $\left[\mathrm{Mn}^{\mathrm{III}}{ }_{9}\right]$ defect supertetrahedron. The Jahn-Teller axes of the $\mathrm{Mn}$ (III) ions are perpendicular to both the $\left[\mathrm{Mn}_{3}^{\mathrm{III}}\right]$ and $\left[\mathrm{Mn}^{\mathrm{III}}{ }_{6}\right]$ planes and are approximately co-parallel to each other (Fig. S1 $\dagger$ ). The crystal packing and intermolecular interactions are shown in Fig. S2-S4. $\dagger$

Direct-current (d.c.) magnetic susceptibility studies in a magnetic field, $B$, of $0.1 \mathrm{~T}$, were performed on polycrystalline 1, the purity of which was confirmed by powder X-ray diffraction (Fig. S5 $\dagger$ ). The $\chi T$ versus $T$ data, where $\chi=M / B$, with $M$ the magnetization, $\chi$ the molar magnetic susceptibility and $T$ the temperature, are shown in Fig. 2. The $\chi T$ product of 1 at $270 \mathrm{~K}$ is $23.2 \mathrm{~cm}^{3} \mathrm{~K} \mathrm{~mol}^{-1}$, lower than that expected for the spin-only contributions of nine uncorrelated $\mathrm{Mn}$ (III) ions $\left(27 \mathrm{~cm}^{3} \mathrm{~K}\right.$

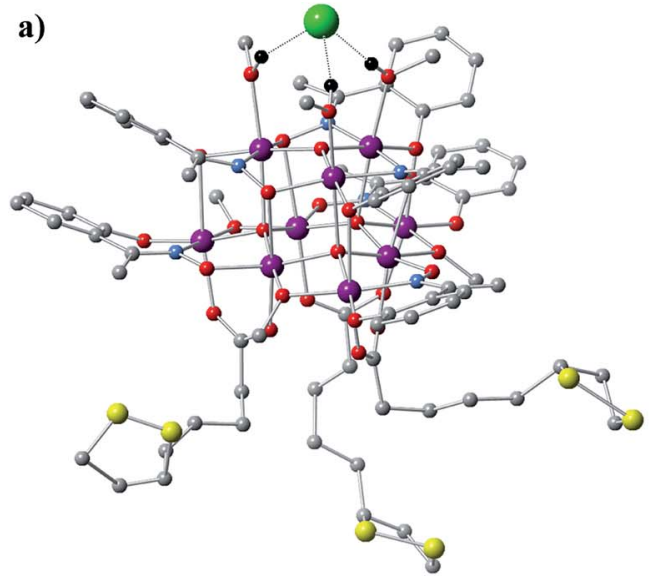

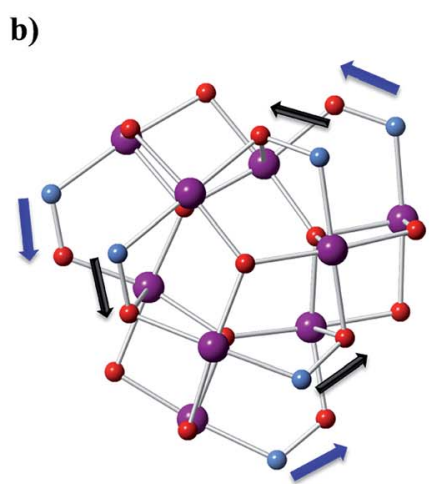

$\Lambda \Lambda$

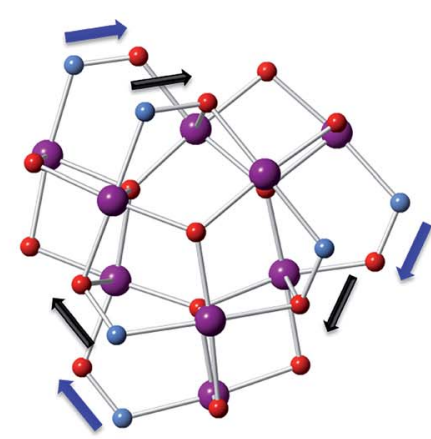

$\Delta \mathbf{\Delta}$

Fig. 1 Structure of $\left[\mathrm{Mn}_{9} \mathrm{O}_{4}(\mathrm{Me}-\mathrm{saO})_{6}(\mathrm{~L})_{3}(\mathrm{MeO})_{3}(\mathrm{MeOH})_{3}\right] \mathrm{Cl}$. (a) Molecular structure of 1. Color scheme: $\mathrm{Mn}-$ purple, $\mathrm{N}-$ blue, $\mathrm{O}-\mathrm{red}, \mathrm{C}-\mathrm{gray}$, $\mathrm{S}$ - yellow, $\mathrm{Cl}$ - green. Hydrogen atoms have been omitted for clarity, except those of the methanol molecules (black) that form $\mathrm{H}$-bonds with the $\mathrm{Cl}^{-}$counter-anion. (b) $\mathbf{\Lambda} \boldsymbol{\Lambda}$ and $\boldsymbol{\Delta} \boldsymbol{\Delta}$ configurations of the $\left[\mathrm{Mn}_{9}{ }_{9}\right]$ core in $\mathbf{1}$. 

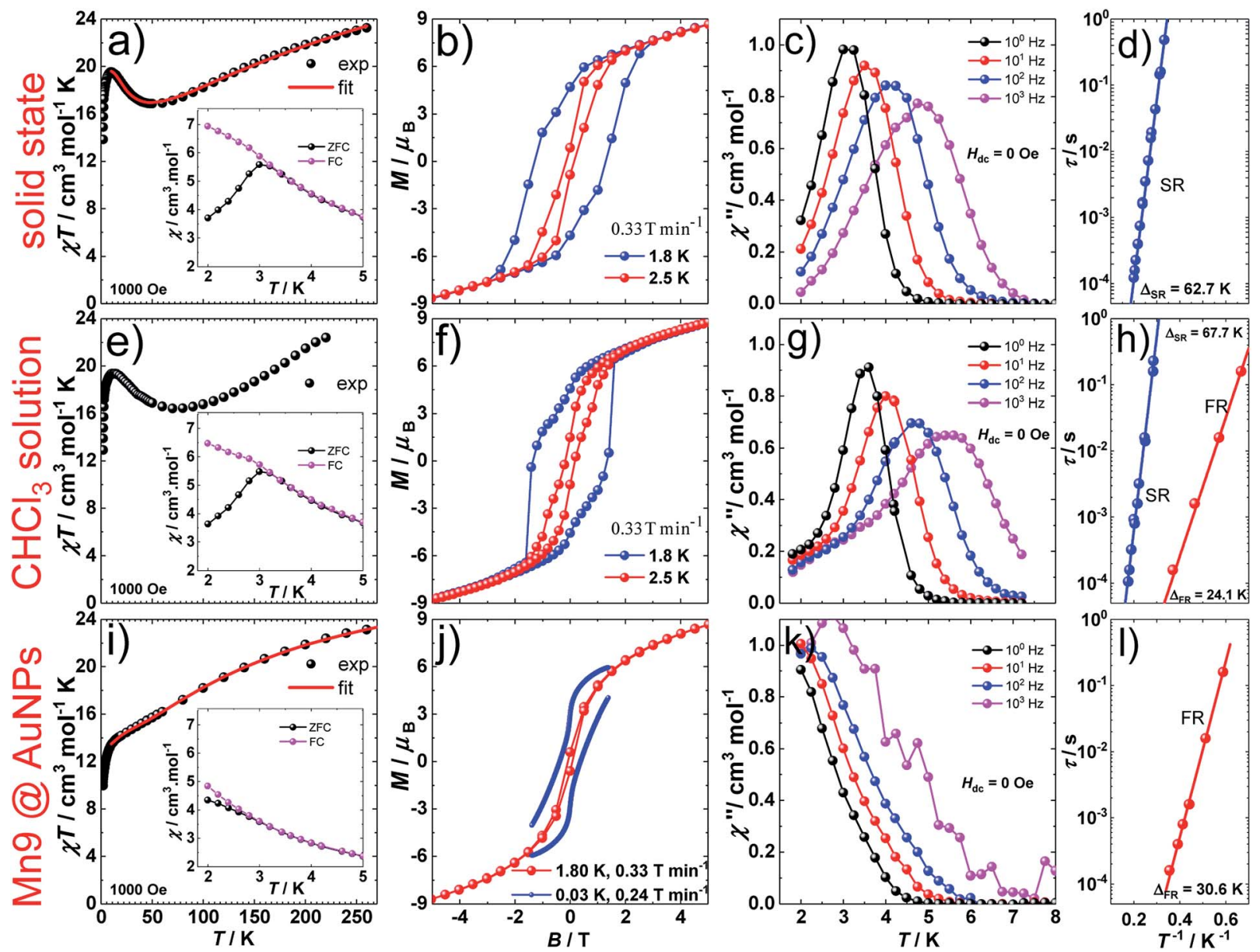

Fig. 2 Magnetic properties of $\left[\mathrm{Mn}_{9} \mathrm{O}_{4}(\mathrm{Me}-\mathrm{sao})_{6}(\mathrm{~L})_{3}(\mathrm{MeO})_{3}(\mathrm{MeOH})_{3}\right] \mathrm{Cl}$. Solid state $(\mathrm{a}-\mathrm{d}), 19.6 \mathrm{mM} \mathrm{CHCl}$ solution $(\mathrm{e}-\mathrm{h})$ and on AuNPs $(\mathrm{i}-\mathrm{l})$. a, e, i, $\chi T$ versus $T$ plots at $0.1 \mathrm{~T}$, with $\chi=M / B$ the molar magnetic susceptibility of 1 , inset: ZFC and FC susceptibility measurements in an applied d.c. field of $0.1 \mathrm{~T} ; \mathrm{b}, \mathrm{f}, \mathrm{j}, \mathrm{d} . \mathrm{c}$. magnetization hysteresis loops at 1.8 and $2.5 \mathrm{~K}$ and $0.33 \mathrm{~T} \mathrm{~min}^{-1}(\mathrm{~b}, \mathrm{f})$ and at $1.8 \mathrm{~K}$ and $0.33 \mathrm{~T} \mathrm{~min} \mathrm{~m}^{-1}$ and at $0.03 \mathrm{~K}$ and 0.24 $\mathrm{T} \mathrm{min}^{-1}$ (j); c, g, K, out-of-phase, $\chi^{\prime \prime}$, component of the a.c. susceptibility at $10^{0}, 10^{1}, 10^{2}$ and $10^{3} \mathrm{~Hz}$ at $T<8 \mathrm{~K}$, in a $3.5 \mathrm{Oe}$ a.c. field and in zero d.c. field. Solid lines are guides for the eye; d, h, l, Arrhenius $\tau$ vs. $T^{-1}$ plot in zero d.c. field for the fast-relaxing (FR) and slow-relaxing (SR) species. The solid lines represent the best fit to the Arrhenius law of the frequency and temperature dependent $\chi^{\prime \prime}$ data.

$\mathrm{mol}^{-1}, S_{\mathrm{Mn}}=2, g_{\mathrm{Mn}}=2$ ). Upon cooling, the $\chi T$ product decreases to reach $16.7 \mathrm{~cm}^{3} \mathrm{~K} \mathrm{~mol}^{-1}$ at $50 \mathrm{~K}$, indicative of dominant antiferromagnetic interactions in 1 . Below $50 \mathrm{~K}$, the $\chi T$ product increases to $19.5 \mathrm{~cm}^{3} \mathrm{~K} \mathrm{~mol}^{-1}$ at $10 \mathrm{~K}$. Upon further cooling, $\chi T$ decreases rapidly to $13.6 \mathrm{~cm}^{3} \mathrm{~K} \mathrm{~mol}^{-1}$, most likely because of the anisotropy of $\mathrm{Mn}$ (III) ions. The nesting and the absence of magnetization saturation in the reduced magnetisation curves for polycrystalline 1 (Fig. S20†), confirms its magnetic anisotropy. A bifurcation between the zero-fieldcooled (ZFC) and field-cooled (FC) susceptibilities (Fig. 2) indicates a blocking temperature, $T_{\mathrm{B}}$, of $3 \mathrm{~K}$. Below $T_{\mathrm{B}}$, magnetic hysteresis (coercive field of $1.3 \mathrm{~T}$ at $1.8 \mathrm{~K}$ and $0.33 \mathrm{~T} \mathrm{~min}^{-1}$ ) is observed (Fig. 2), which is the experimental manifestation of SMM (superparamagnetic-like) behavior.

Modeling of the static magnetic properties of $\mathbf{1}$ on the basis of a spin-Hamiltonian is far from straightforward because of the large dimension $\left(5^{9}=1953125\right)$ of the associated spinHamiltonian matrix. Within an isotropic model, use of Irreducible Tensor Operator (ITO) algebra ${ }^{40}$ allows blocking of the spin-Hamiltonian matrix into nineteen blocks (ESI $§ 6.2 \dagger$ ), each corresponding to a given value of the total spin, $S$. Thus, the $180325 S$ multiplets of 1 (Table S8†), with $S$ varying between 0 and 18, were grouped into nineteen blocks of dimensions ranging from $1(S=18)$ to $25200(S=4)$. These were subsequently numerically diagonalized by use of standard techniques. ${ }^{41}$ The temperature dependence of the $\chi T$ product of $\mathbf{1}$ was numerically fitted, down to $10 \mathrm{~K}$, to an isotropic spinHamiltonian model by use of the Levenberg-Marquardt algorithm. ${ }^{42}$ To avoid overparameterization, we considered the simplest model of magnetic exchange in 1 (ESI $\S 6.2 \dagger$ ), where $J_{1}$, $J_{2}$ and $J_{3}$ are the isotropic exchange parameters within [ $\left[\mathrm{Mn}_{6}^{\mathrm{III}}\right]$, $\left[\mathrm{Mn}_{3}{ }_{3}\right]$ and between $\left[\mathrm{Mn}_{6}{ }_{6}\right]$ and $\left[\mathrm{Mn}_{3}{ }_{3}\right]$, respectively (Fig. S32†). This resulted in the best fit parameters: $J_{1}=$ $-7.6 \mathrm{~cm}^{-1}, J_{2}=1.8 \mathrm{~cm}^{-1}$ and $J_{3}=-1.6 \mathrm{~cm}^{-1}$ (in the $-2 J$ convention). These results are in excellent agreement with previous magnetostructural correlations developed for similar oxime-bridged Mn(III)-based SMMs, where Mn-N-O-Mn torsion angles above or below $31^{\circ}$ lead to ferromagnetic $(J>0)$ or antiferromagnetic $(J<0)$ interactions, respectively. ${ }^{43,44}$ Within this highly symmetric isotropic model, the ground spin state of $\mathbf{1}$ is 
a doubly degenerate $S=5$ with numerous excited multiplets lying very low in energy (Fig. S33a $\dagger$ ). However, given the magnetically anisotropic nature of $\mathrm{Mn}$ (III), description of the low temperature magnetic properties of 1 in terms of $S$ multiplets is meaningless, since the anisotropy-induced splitting of the $m_{\mathrm{s}}$ sublevels of these $S$-multiplets is much larger (Fig. S35, Table S9 $\dagger$ ) than the isotropic exchange induced splitting between $S$-multiplets (Fig. S33a $\dagger$ ). Use of an iterative subspace approach, known as the Davidson algorithm, ${ }^{45,46}$ that exploits the sparse nature of the spin-Hamiltonian matrix, ${ }^{47,48}$ allowed exact determination of the 32 lowest lying eigenvalues and eigenvectors (ESI $\$ 6.2 \dagger$ ). This subspace was subsequently used to model the low temperature magnetic properties of $\mathbf{1}$ (Fig. S34 $\dagger$ ) allowing estimation of the single-ion uniaxial anisotropy of $\mathrm{Mn}(\mathrm{III}), D_{\mathrm{Mn}}=-3.4 \mathrm{~cm}^{-1}$.

The spin-dynamics of $\mathbf{1}$ was probed by alternating current (a.c.) magnetic susceptibility measurements, revealing frequency and temperature dependent in-phase $\left(\chi^{\prime}\right)$ and out-ofphase $\left(\chi^{\prime \prime}\right)$ components (Fig. 2, S21 and S22 $\dagger$ ). These were used to extract the energy barrier of the thermally activated process, $\Delta_{\text {eff }}$, by fitting the relaxation time, $\tau$, to the Arrhenius law $\tau=$ $\tau_{0} \exp \left(\Delta_{\text {eff }} / k_{\mathrm{B}} T\right)$, with $k_{\mathrm{B}}$ the Boltzmann constant and $\tau_{0}$ a preexponential factor, resulting in: $\Delta_{\text {eff }} / k_{\mathrm{B}}=62.7 \mathrm{~K}$ and $\tau_{0}=4.0$ $\times 10^{-10} \mathrm{~s}$.

\section{Solution}

Since single crystals of $\mathbf{1}$ are very dark, preventing solid state optical activity measurements, we performed these on chloroform solutions of individual single-crystals of 1. Circular Dichroism (CD) spectra showed mirror-image Cotton effects at several wavelengths (Fig. 3). The higher intensity bands below $330 \mathrm{~nm}$ are attributed to charge-transfer ${ }^{25}$ (CT) and/or internal ligand transitions ${ }^{49}$ (Fig. S19 $\dagger$ ). The weaker bands observed above $330 \mathrm{~nm}$ are attributed to the seven possible $\mathrm{d}-\mathrm{d}$ transitions for Mn(III) in a low-symmetry crystal field. ${ }^{25}$ The solution CD spectra of the enantiomers of $\mathbf{1}$ show that it does not

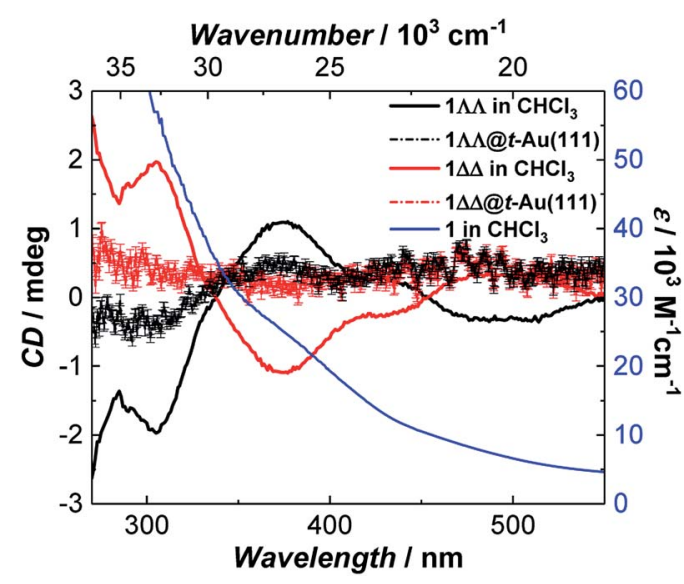

Fig. 3 Room temperature absorption spectrum of 1 (blue) and circular dichroism spectra of $\mathbf{1} \mathbf{\Delta} \mathbf{\Delta}$ (red) and $\mathbf{1} \mathbf{\Lambda} \mathbf{\Lambda}$ (black) in $\mathrm{CHCl}_{3}$ (background corrected data, see ESI $\dagger$ ) and as monolayers on Au(111) (raw data). The intensity of $1 \mathbf{\Lambda} \Lambda \mathrm{at}-\mathrm{Au}(111)$ and $1 \Delta \Delta \mathrm{at}-\mathrm{Au}(111)$ was multiplied by a factor of 10 to increase its visibility. racemize or decompose in solution. Further evidence of the stability of 1 in solution was obtained by infrared (IR) spectroscopy (Fig. S6†) and mass spectrometry (Fig. S7†).

D.c. magnetization measurements on $19.6 \mathrm{mM}$ chloroform solutions of 1 revealed very similar behavior to that observed in the solid state (Fig. 2). The temperature dependence of the $\chi T$ product, $T_{\mathrm{B}}$, and the magnetic hysteresis of the frozen solution of $\mathbf{1}$ are very similar to the analogous measurements in the solid state (Fig. 2), reflecting the structural integrity of $\mathbf{1}$ in solution. A.c. susceptibility measurements on $19.6 \mathrm{mM}$ chloroform solutions (Fig. 2, S23 and S24 $\dagger$ ) showed the presence of a slowrelaxing (SR) and a fast-relaxing (FR) process. Since the molecular spin-dynamics is extremely sensitive to the coordination sphere of the metal centres, ${ }^{\mathbf{5 0 , 5 1}}$ these are attributed to a SR and a FR species, for which we obtain: $\Delta_{\mathrm{eff}} / k_{\mathrm{B}}$ of 66.7 and $24.1 \mathrm{~K}$ and $\tau_{0}=8.2 \times 10^{-10}$ and $1.6 \times 10^{-8} \mathrm{~s}$, respectively. Magnetization measurements on a $6.8 \mathrm{mM}$ chloroform solution of 1 showed an increase in the FR species (Fig. S25 and S26†). This observation suggests the loss of terminal $\mathrm{MeOH}$ ligands upon dissolution, leading to the modification of the axial anisotropy of Mn(III) centres and/or to a change in the Mn(III) Jahn-Teller axis orientation at these centres. ${ }^{52,53}$

\section{Surface deposition}

1 was chemically grafted on several metallic gold substrates by exploiting the high affinity of sulfur for gold ${ }^{54,55}$ (40-

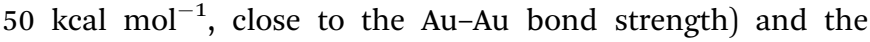
tripodal ligand nature of $\mathbf{1}$. These were: (a) gold nanoparticles, AuNPs, used to increase the specific surface area of the substrate for the study of the magnetic properties of grafted 1 (1@AuNPs) by conventional magnetometry; ${ }^{56}$ (b) transparent $\mathrm{Au}(111)$ surface, ${ }^{57} \boldsymbol{t}$-Au(111), to allow probing of the optical activity of grafted $\mathbf{1} \Lambda \Lambda$ and $\mathbf{1 \Delta \Delta}(\mathbf{1} \Lambda \Lambda @ t-\mathbf{A u}(\mathbf{1 1 1})$ and $\mathbf{1 \Delta \Delta}$ @t $\mathbf{A u ( 1 1 1 ) , ~ r e s p e c t i v e l y ) ; ~ a n d ~ ( c ) ~ e p i t a x i a l ~} \mathrm{Au}(111)$ surface, $\boldsymbol{e}-\mathbf{A u}(\mathbf{1 1 1})$, to study the organization of $\mathbf{1}$ on this substrate (1@e-Au(111)).

1@AuNPs were obtained from hexadecylamine (HDA) capped AuNPs (HDA@AuNPs) of $7.3 \mathrm{~nm}$ average size, as determined by Transmission Electron Microscopy (TEM, Fig. 4, S8 and $\mathrm{S} 9 \dagger)$. Taking into account some simple geometric calculations, ${ }^{56}$ a $10 \%$ by weight ratio of 1 is necessary to achieve full coverage. Upon grafting, the dark red color of HDA@AuNPs changed to red-violet for 1@AuNPs (plasmon resonances at 522 and $542 \mathrm{~nm}$, respectively, Fig. 4), indicating a change of dielectric constant around the AuNPs. ${ }^{58}$ To confirm grafting of 1 on AuNPs rather than adsorption, X-ray Photoelectron Spectroscopy (XPS) measurements of 1, HDA@AuNPs and 1@AuNPs were carried out on the Au4f, Au4p, Mn3s, Mn2p, S2p, Cl2p, N1s, O1s and C1s regions of binding energies (Fig. 5a, S10-S12 and Tables S8-S10 $\dagger$ ). The photoemission of 1@AuNPs allowed confirmation of the presence of $\mathrm{Mn}, \mathrm{S}$, and $\mathrm{Cl}$. These elements are not present or have different binding energies in HDA@AuNPs when compared to 1 . The S2p region is particularly interesting because $\mathrm{S} 2 \mathrm{p}_{3 / 2}$ peaks at $161.8-161.9 \mathrm{eV}$ are assigned to thiols bound to the Au surface while $S 2 \mathrm{p}_{3 / 2}$ peaks at 163.2-163.5 eV are consistent with unbound thiols/disulfides. ${ }^{59}$ 

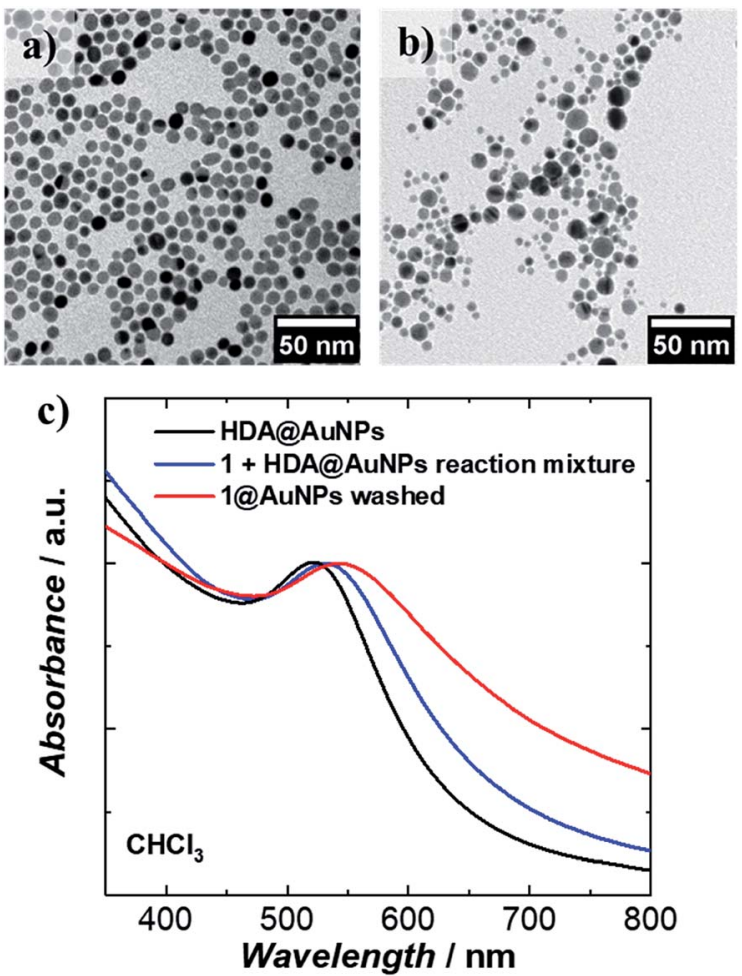

Fig. 4 Transmission Electron Microscopy (TEM) images of (a) HDA@AuNPs and (b) evenly distributed 1@AuNPs formed after the deposition of 1 on AuNPs; (c) plasmon resonance spectra of HDA@AuNPs and 1@AuNPs.

The observed shift of the $\mathrm{S} 2 \mathrm{p}_{3 / 2}$ bands from $163.5 \mathrm{eV}$ (1) to $161.9 \mathrm{eV}$ (1@AuNPs) of binding energy (and of the less intense S2 $\mathrm{p}_{1 / 2}$ bands from $164.7 \mathrm{eV}$ (1) to $162.8 \mathrm{eV}$ (1@AuNPs)) and the change of their intensity profile (Fig. 5a and S11†) shows that sulfur is reduced upon binding to $\mathrm{Au},{ }^{59,60}$ confirming grafting of 1. Information on the surface stoichiometry (Tables S8 and S9†) was derived by quantitative analysis of the XPS spectra. The stability of $\mathbf{1}$ upon deposition on AuNPs can be confirmed by the
$\mathrm{Mn} / \mathrm{S}$ ratio values since these elements are not present in HDA@AuNPs. The measured Mn/S ratio in 1 and in 1@AuNPs fits well with the expected stoichiometric value (Table S9†), whereas $\mathrm{S} / \mathrm{N}, \mathrm{Mn} / \mathrm{N}$, and $\mathrm{S} / \mathrm{Cl}$ ratios are lower than the expected ones in 1@AuNPs suggesting that elements such as $\mathrm{N}$ and $\mathrm{Cl}$ are present in excess likely due to their high content on the surface of HDA@AuNPs used as starting material in the preparation of 1@AuNPs. Mn(III)-based SMMs often undergo reduction to Mn(II)-containing species upon deposition on gold. ${ }^{61}$ The XPSderived modified Auger parameter (Table S11†), insensitive to charging of non-conducting specimens, has the same value (within standard deviation) for 1, 1@AuNPs and 1@Au(111), suggesting a constant oxidation state in the three samples. ${ }^{\mathbf{6 2 , 6 3}}$ However, since in XPS, intense Au4f peaks totally cover the Mn3s signals, and Au4p partially interferes with the weak Mn2p signals (Fig. S12 $\dagger$ ), we performed X-ray absorption spectroscopy (XAS) to compare the oxidation state of $\mathrm{Mn}$ in $\mathbf{1}$ and in 1@AuNPs. The experimental X-ray absorption spectra (Fig. 5b) are dominated by the $1 \mathrm{~s}$ to $4 \mathrm{p}$ transitions with a much weaker pre-edge feature, assigned to dipole-forbidden $1 \mathrm{~s}$ to $3 \mathrm{~d}$ transitions. This energetically low-lying pre-edge feature, being weakly dependent on the exact ligand field, is usually taken as a fingerprint of the oxidation state of a transition metal. The Mn K-edge spectra of $\mathbf{1}$ and of $\mathbf{1} @ A u N P s$ reveal a remarkable similarity, confirming that $\mathrm{Mn}$ is in the same oxidation state in both systems. By comparison to published Mn(III) K-edge absorption spectra, ${ }^{\mathbf{6 4 6 5}}$ we can conclude that the oxidation state of Mn in $\mathbf{1}$ and 1@AuNPs is +III. Furthermore, both 1 and 1@AuNPs display very weak X-ray Magnetic Circular Dichroism (XMCD) at the Mn K-edge (Fig. S13 $\dagger$ ). At the K-edge of a transition metal ion, the XMCD signal is due to the orbital magnetization of the $4 \mathrm{p}$ - and 3d-states, induced by the intra-atomic spin-orbit interaction. The XMCD spectrum of 1 (Fig. S13†) reveals several clear features in the pre-edge, at the edge and also characteristic super-Coster-Kronig multi-electron excitations at $\sim 47 \mathrm{eV}$ above the edge. ${ }^{66}$ However, the amplitude of the XMCD signal of 1 is found to be nearly 100 times weaker than the one detected in a)

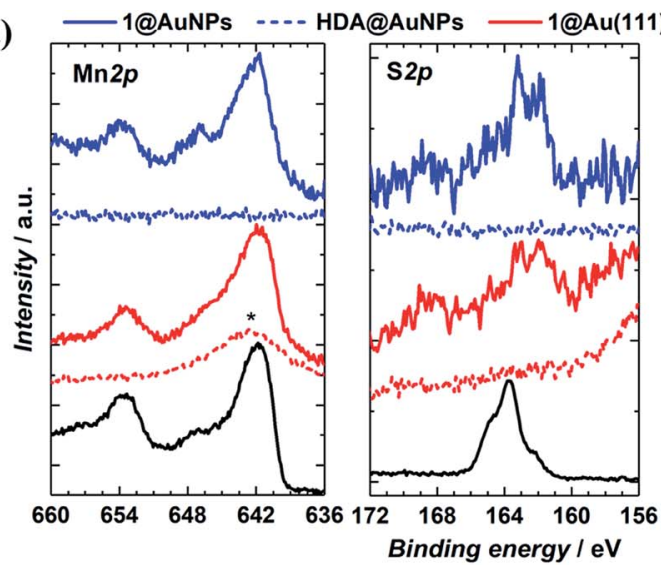

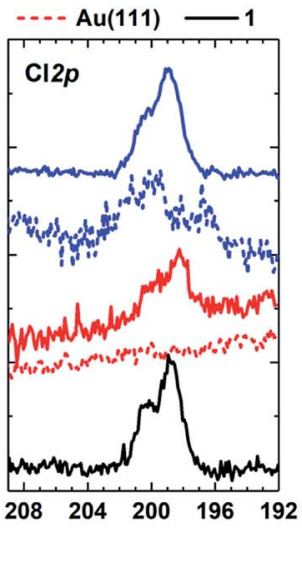

b)

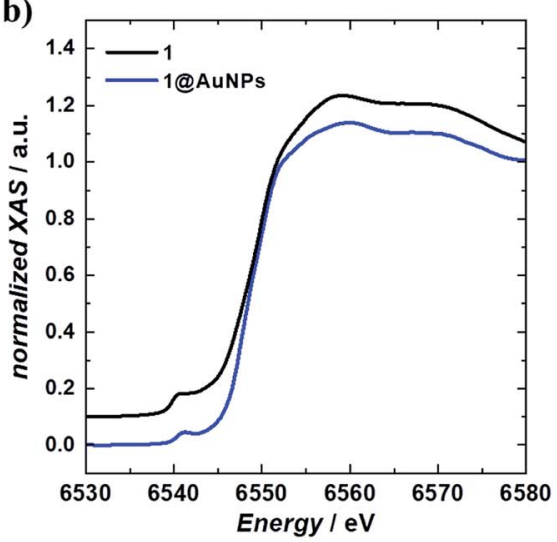

Fig. 5 XPS and XAS spectra of bulk and surface deposited $\left[\mathrm{Mn}_{9} \mathrm{O}_{4}(\mathrm{Me}-\mathrm{sao})_{6}(\mathrm{~L})_{3}(\mathrm{MeO})_{3}(\mathrm{MeOH})_{3}\right] \mathrm{Cl}$. (a) XPS spectra of 1, 1@AuNPs, 1@Au(111), HDA@AuNPs, and blank Au(111) surface at Mn2p, S2p and Cl2p core levels. The Mn2p $3 / 2$ core level line in 1@Au(111) is superimposed on the Au $4 p_{1 / 2}$ feature, marked with *; (b) Normalised XAS spectra of 1 and 1 (aAuNPs, the intensity of the former is shifted by 0.1 a.u. for clarity of presentation. 
paramagnetic $\mathrm{Mn}^{3+}$ ions in $\mathrm{GaN}^{67}$ This observation indicates significant quenching of orbital moments in $\mathbf{1}$.

1@AuNPs, HDA@AuNPs and HL@AuNPs were investigated in the solid state with SQUID magnetometry. AuNPs are known to display magnetic properties ranging from diamagnetism, through paramagnetism, to ferromagnetism, depending on the type of surface ligand and the degree of coverage. ${ }^{68-75}$ The $\chi T$ product of 1@AuNPs at $270 \mathrm{~K}$ is $22.2 \mathrm{~cm}^{3} \mathrm{~K} \mathrm{~mol}^{-1}$, slightly lower than the $23.2 \mathrm{~cm}^{3} \mathrm{~K} \mathrm{~mol}^{-1}$ seen for 1 (Fig. 2). Between 270 and $60 \mathrm{~K}$ the $\chi T$ product decreases to a value of $15.7 \mathrm{~cm}^{3} \mathrm{~K} \mathrm{~mol}^{-1}$, following the trend observed in 1. On further cooling, the $\chi T$ product for 1@AuNPs continues to decrease, contrary to 1, until it reaches a plateau around $18.5 \mathrm{~cm}^{3} \mathrm{~K} \mathrm{~mol}^{-1}$ between 25 and 10 K. Below $10 \mathrm{~K}, \chi T$ abruptly decreases, as in 1 , to $9.6 \mathrm{~cm}^{3} \mathrm{~K} \mathrm{~mol}^{-1}$ at $1.8 \mathrm{~K}$. Fitting of the temperature dependence of the $\chi T$ product for 1@AuNPs to the same spin-Hamiltonian model as for 1 , resulted in the best-fit parameters: $J_{1}=-4.5 \mathrm{~cm}^{-1}, J_{2}=$ $2.7 \mathrm{~cm}^{-1}$ and $J_{3}=-2.8 \mathrm{~cm}^{-1}$. Thus, the absence of a maximum in the $\chi T$ product of $1 @ A u N P s$ at $10 \mathrm{~K}$ is mainly due to the modification of the magnetic exchange interactions within the $\left[\mathrm{Mn}_{6}\right]$ subunit $\left(J_{1}\right)$ as a consequence of the distortion of the $\left[\mathrm{Mn}_{9}\right]$ core upon grafting to the AuNPs surface via the sulfurcontaining carboxylates bound to the $\left[\mathrm{Mn}_{6}\right]$ subunit. This modification could be assigned to $\mathrm{Mn}-\mathrm{N}-\mathrm{O}-\mathrm{Mn}$ torsion angles within the $\left[\mathrm{Mn}_{6}\right]$ subunit evolving from $7.9-13.3^{\circ}$ (Tables $\mathrm{S} 2$ and $\mathrm{S} 3 \dagger$ ), corresponding to $J_{1}=-7.6 \mathrm{~cm}^{-1}$, towards the $31^{\circ}$ limit. $^{43,44}$ In fact, a previously reported $\left[\mathrm{Mn}_{9}\right]$ complex presenting a very similar temperature dependence of the $\chi T$ product to 1@AuNPs displayed $\mathrm{Mn}-\mathrm{N}-\mathrm{O}-\mathrm{Mn}$ torsion angles of $25^{\circ}$ within the $\left[\mathrm{Mn}_{6}\right]$ subunit. ${ }^{65}$ The reduced magnetization curves show no saturation and are not superimposable (Fig. S20†), again confirming the magnetically anisotropic nature of 1@AuNPs. The magnetization of 1@AuNPs at $1.8 \mathrm{~K}$ and at $5 \mathrm{~T}$ is $8.7 \mu_{\mathrm{B}}$, similar to the solid state. A less well pronounced bifurcation between the ZFC and FC susceptibility curves was observed at $3 \mathrm{~K}$ for 1@AuNPs (Fig. 2). 1@AuNPs exhibits magnetic hysteresis (Fig. 2 and S29†) with a coercive field of $0.08 \mathrm{~T}$ at $1.8 \mathrm{~K}$ and $0.33 \mathrm{~T} \mathrm{~min}^{-1}$ and of $0.38 \mathrm{~T}$ at $0.03 \mathrm{~K}$ and $0.24 \mathrm{~T} \mathrm{~min}^{-1}$. The magnetization observed at low temperatures for 1@AuNPs was several orders of magnitude higher than for HDA@AuNPs or HL@AuNPs (Fig. S28 and S29 $\dagger$ ). Temperature and frequency dependent $\chi^{\prime}$ and $\chi^{\prime \prime}$ components of the a.c. susceptibility were observed (Fig. 2 and $\mathrm{S} 27 \dagger$ ) at zero d.c. field from where $\Delta_{\text {eff }} / k_{\mathrm{B}}=30.6 \mathrm{~K}$ and $\tau_{0}=2.4 \times 10^{-9} \mathrm{~s}$ were determined. HDA@AuNPs and HL@AuNPs displayed no such features (Fig. S28-S30 $\dagger$ ). The values of $\Delta_{\mathrm{eff}}, T_{\mathrm{B}}$, and of the coercive field for 1@AuNPs point towards grafting of the FR species on AuNPs. This is due to the loss of $\mathrm{MeOH}$, and the possible ensuing reorientation of the Jahn-Teller axis, caused by the multiple washing cycles during the surface deposition of $\mathbf{1}$.

Monolayers of 1@e-Au(111), 1@t-Au(111), $1 \Lambda \Lambda @ t-A u(111)$ and $\mathbf{1} \Delta \mathbf{\Delta} @ \boldsymbol{t}$-Au(111), hereafter collectively referred to as 1@Au(111), were prepared by soaking $\boldsymbol{e}-\mathbf{A u}(\mathbf{1 1 1})$ or $\boldsymbol{t}$-Au(111) films in $2 \mathrm{mM}$ solutions of $\mathbf{1}, \mathbf{1} \boldsymbol{\Lambda} \boldsymbol{\Lambda}$ or $\mathbf{1 \Delta \Delta}$ in chloroform, followed by extensive washing with chloroform. All monolayers were characterised by XPS. The observed binding energies and lineshapes of equivalent XPS bands are the same for 1@AuNPs and 1@Au(111) (Fig. 5 and S10-S12†), confirming the redox integrity of $\mathbf{1}$ and its grafting to form a monolayer. Stoichiometric analysis of the XPS spectra (Table $\mathrm{S} 8 \dagger$ ) showed that the $\mathrm{Mn} / \mathrm{S}$ and $\mathrm{Mn} / \mathrm{N}$ ratios measured for 1@Au(111) (Table S19 $\dagger$ ) are higher than the corresponding values for 1 or 1@AuNPs, suggesting a higher Mn content. The observed excess could be caused by the intense Au4f peaks totally superposing the Mn3s signals and Au4p partially interfering with the weak Mn2p signals (Fig. 5a and S12†). The measured value for the $\mathrm{S} / \mathrm{N}$ ratio is in good agreement with the value measured in $\mathbf{1}$. Since $\mathrm{S}$ and $\mathrm{N}$ were not detected on the clean $\mathrm{Au}(111)$ surface, the value of $\mathrm{S} / \mathrm{N}$ ratio for $\mathbf{1} @ \mathbf{A u}(\mathbf{1 1 1})$ can be considered an indirect indication of the $\left[\mathrm{Mn}_{9}\right]$ stability during the deposition process.

Surface coverage was imaged by Atomic Force Microscopy (AFM) of 1@e-Au(111) (Fig. 6 and S14-S16†). Comparison of the pristine $\boldsymbol{e}$-Au(111) surface (Fig. 6a) with this of 1@e-Au(111) (Fig. 6b) shows monolayer coverage of the $\mathrm{Au}(111)$ facets with isolated protrusions being distributed across the surface. The heights of these individual protrusions range from 0.5 to $1.1 \mathrm{~nm}$, with an average of $0.7 \mathrm{~nm}$ (Fig. S16†). This length distribution corresponds well to the length distribution obtained by considering a model where the three sulfur-containing carboxylate bridging ligands either "stand fully elongated" on the Au surface or "lie flat" on it (Fig. S17†). Such a distribution of topologies would create
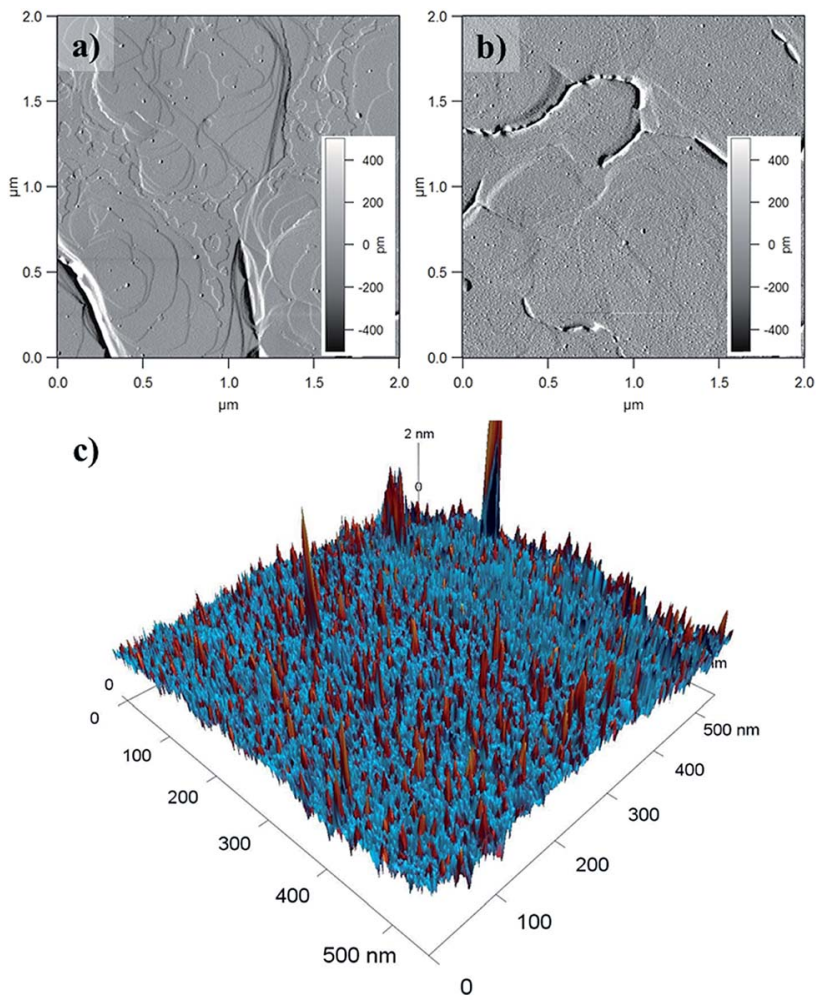

Fig. 6 AFM amplitude mode images of (a) e-Au(111) clean surface with visible atomic steps and (b) 1@e-Au(111). (c) 3D combined phase and height AFM taping-mode profiles of 1@e-Au(111). Red and blue tapingmode phases correspond to different compressibilities of the deposited material. Individual protrusions coincide with the red phase. 
a difference of compressibility in the deposited monolayer since the $\left[\mathrm{Mn}_{9}\right]$ metal core is less compressible than the sulfur-containing carboxylates standing fully elongated on the $\mathrm{Au}(111)$ surface. This is confirmed by the phase of the AFM taping-mode image (color mapping in Fig. 6c) where individual protrusions also correspond to a change in the AFM phase. A more detailed insight over the organization of the molecules of 1 on the $\mathrm{Au}(111)$ surface, though could be offered by high resolution and low temperature scanning tunneling microscopy combined with angle dependent X-ray magneto-circular and/or linear dichroisms. ${ }^{34,76}$

CD spectra of monolayers of $\mathbf{1} \Lambda \Lambda @ t-A u(111)$ and $\mathbf{1} \Delta \Delta @ t$ Au(111) showed mirror-image Cotton effects below $450 \mathrm{~nm}$ (Fig. 3 and $\mathrm{S} 19 \dagger$ ) corresponding to $\mathrm{d}-\mathrm{d}$ and CT bands in 1, in very close agreement to the CD spectra observed for solutions of single crystals of $\mathbf{1}$. These observations confirm both the deposition of enantiopure 1 on $\mathrm{Au}(111)$ and the structural stability of 1 upon surface deposition from solution. The structural integrity of $\mathbf{1}$ upon deposition on $\boldsymbol{t}$-Au(111) was also confirmed with ATR FT-IR. The obtained IR spectrum of 1@t$\mathbf{A u}(\mathbf{1 1 1})$ is superimposable on that of crystalline $\mathbf{1}$ (Fig. S18 †) in the 2000-650 $\mathrm{cm}^{-1}$ spectral region, with no stretching vibrations specific to the free ligands $\left(\mathrm{Me}-\mathrm{saoH}_{2}\right.$ or $\mathrm{HL}$, Fig. S6†).

\section{Conclusions}

We have demonstrated that, by exploiting the power of synthetic chemistry and by taking advantage of the chemical affinity of sulfur for gold, we were able to deposit a chiral SMM on a metallic surface, preserving its molecular multifunctionality (superparamagnetism-like behaviour and optical activity) from the solid state, via dissolution, to the surface deposited species. The observed magnetic properties of the enneannucler Mn(III)based SMM are explained qualitatively on the basis of established magnetostructural correlations, and quantitatively within the spin-Hamiltonian formalism by use of ITO algebra and of an iterative subspace approach, known as the Davidson algorithm. Future efforts will focus on addressing these surfacedeposited chiral SMMs by electric fields via spin-electric coupling, and by light via the magnetochiral effect. This will pave the way for the integration of molecular magnetic chiral materials in molecular quantum spintronics devices, the use of which will revolutionize the way we perceive and manipulate information.

\section{Conflicts of interest}

There are no conflicts to declare.

\section{Acknowledgements}

SP thanks VILLUM FONDEN for research grant 13376. EKB thanks the EPSRC (EP/P025986/1 and EP/N01331X/1) for funding. WW acknowledges ERC Advanced Grant Moquos No. 741276. The European Synchrotron Radiation Facility is acknowledged for measurements (CH-5014) on beamline ID12.

\section{Notes and references}

1 C. Chappert, A. Fert and F. N. Van Dau, Nat. Mater., 2007, 6, 813-823.

2 A. R. Rocha, V. M. Garcia-Suarez, S. W. Bailey, C. J. Lambert, J. Ferrer and S. Sanvito, Nat. Mater., 2005, 4, 335-339.

3 L. Bogani and W. Wernsdorfer, Nat. Mater., 2008, 7, 179-186. 4 A. Cornia, M. Mannini, P. Sainctavit and R. Sessoli, Chem. Soc. Rev., 2011, 40, 3076-3091.

5 A. Cornia and M. Mannini, in Molecular Nanomagnets and Related Phenomena, ed. S. Gao, Springer Berlin Heidelberg, Berlin, Heidelberg, 2015, pp. 293-330.

6 A. Cornia and M. Mannini, Single-Molecule Magnets on Surfaces, Springer-Verlag, Berlin Heidelberg, 2014.

7 A. Cornia, D. R. Talham and M. Affronte, in Molecular Magnetic Materials: Concepts and Applications, ed. B. Sieklucka and D. Pinkowicz, Wiley - VCH Verlag $\mathrm{GmbH} \&$ Co. KGaA, 2016, pp. 187-229.

8 S. Thiele, F. Balestro, R. Ballou, S. Klyatskaya, M. Ruben and W. Wernsdorfer, Science, 2014, 344, 1135-1138.

9 M. Urdampilleta, S. Klyatskaya, J. P. Cleuziou, M. Ruben and W. Wernsdorfer, Nat. Mater., 2011, 10, 502-506.

10 R. Vincent, S. Klyatskaya, M. Ruben, W. Wernsdorfer and F. Balestro, Nature, 2012, 488, 357-360.

11 M. Trif, F. Troiani, D. Stepanenko and D. Loss, Phys. Rev. Lett., 2008, 101, 217201.

12 G. L. J. A. Rikken and E. Raupach, Nature, 1997, 390, 493494.

13 C. Train, R. Gheorghe, V. Krstic, L. M. Chamoreau, N. S. Ovanesyan, G. L. J. A. Rikken, M. Gruselle and M. Verdaguer, Nat. Mater., 2008, 7, 729-734.

14 R. Sessoli, M. E. Boulon, A. Caneschi, M. Mannini, L. Poggini, F. Wilhelm and A. Rogalev, Nat. Phys., 2015, 11, 69-74.

15 D. Gatteschi, R. Sessoli and J. Villain, Molecular Nanomagnets, Oxford University Press, New York, 2007.

16 C. A. P. Goodwin, F. Ortu, D. Reta, N. F. Chilton and D. P. Mills, Nature, 2017, 548, 439-442.

17 M. N. Leuenberger and D. Loss, Nature, 2001, 410, 789793.

18 F. Meier, J. Levy and D. Loss, Phys. Rev. Lett., 2003, 90, 047901.

19 F. Troiani, A. Ghirri, M. Affronte, S. Carretta, P. Santini, G. Amoretti, S. Piligkos, G. Timco and R. E. P. Winpenny, Phys. Rev. Lett., 2005, 94, 207208.

20 L. Thomas, F. Lionti, R. Ballou, D. Gatteschi, R. Sessoli and B. Barbara, Nature, 1996, 383, 145-147.

21 W. Wernsdorfer and R. Sessoli, Science, 1999, 284, 133-135. 22 K. Bader, D. Dengler, S. Lenz, B. Endeward, S. D. Jiang, P. Neugebauer and J. van Slageren, Nat. Commun., 2014, 5, 5304.

23 M. Mannini, P. Sainctavit, R. Sessoli, C. C. D. Moulin, F. Pineider, M. A. Arrio, A. Cornia and D. Gatteschi, Chem. Eur. J., 2008, 14, 7530-7535.

24 R. Inglis, J. Bendix, T. Brock-Nannestad, H. Weihe, E. K. Brechin and S. Piligkos, Chem. Sci., 2010, 1, 631-636. 
25 J. M. Bradley, A. J. Thomson, R. Inglis, C. J. Milios, E. K. Brechin and S. Piligkos, Dalton Trans., 2010, 39, 9904-9911.

26 L. Bogani, L. Cavigli, M. Gurioli, R. L. Novak, M. Mannini, A. Caneschi, F. Pineider, R. Sessoli, M. Clemente-Leon, E. Coronado, A. Cornia and D. Gatteschi, Adv. Mater., 2007, 19, 3906-3911.

27 M. Mannini, F. Pineider, P. Sainctavit, C. Danieli, E. Otero, C. Sciancalepore, A. M. Talarico, M. A. Arrio, A. Cornia, D. Gatteschi and R. Sessoli, Nat. Mater., 2009, 8, 194-197.

28 M. Mannini, F. Pineider, P. Sainctavit, L. Joly, A. FraileRodriguez, M. A. Arrio, C. C. D. Moulin, W. Wernsdorfer, A. Cornia, D. Gatteschi and R. Sessoli, Adv. Mater., 2009, 21, 167-171.

29 M. Mannini, F. Pineider, C. Danieli, F. Totti, L. Sorace, P. Sainctavit, M. A. Arrio, E. Otero, L. Joly, J. C. Cezar, A. Cornia and R. Sessoli, Nature, 2010, 468, 417-421.

30 L. Bogani, C. Danieli, E. Biavardi, N. Bendiab, A. L. Barra, E. Dalcanale, W. Wernsdorfer and A. Cornia, Angew. Chem., Int. Ed., 2009, 48, 746-750.

31 S. Kyatskaya, J. R. Galan-Mascaros, L. Bogani, F. Hennrich, M. Kappes, W. Wernsdorfer and M. Ruben, J. Am. Chem. Soc., 2009, 131, 15143-15151.

32 A. Hofmann, Z. Salman, M. Mannini, A. Amato, L. Malavolti, E. Morenzoni, T. Prokscha, R. Sessoli and A. Suter, ACS Nano, 2012, 6, 8390-8396.

33 C. Wäckerlin, F. Donati, A. Singha, R. Baltic, S. Rusponi, K. Diller, F. Patthey, M. Pivetta, Y. Lan, S. Klyatskaya, M. Ruben, H. Brune and J. Dreiser, Adv. Mater., 2016, 28, 5142.

34 M. Mannini, F. Bertani, C. Tudisco, L. Malavolti, L. Poggini, K. Misztal, D. Menozzi, A. Motta, E. Otero, P. Ohresser, P. Sainctavit, G. G. Condorelli, E. Dalcanale and R. Sessoli, Nat. Commun., 2014, 5, 4582.

35 V. Corradini, A. Ghirri, E. Garlatti, R. Biagi, V. De Renzi, U. del Pennino, V. Bellini, S. Carretta, P. Santini, G. Timco, R. E. P. Winpenny and M. Affronte, Adv. Funct. Mater., 2012, 22, 3706-3713.

36 A. Ghirri, V. Corradini, C. Cervetti, A. Candini, U. del Pennino, G. Timco, R. J. Pritchard, C. A. Muryn, R. E. P. Winpenny and M. Affronte, Adv. Funct. Mater., 2010, 20, 1552-1560.

37 V. E. Campbell, M. Tonelli, I. Cimatti, J. B. Moussy, L. Tortech, Y. J. Dappe, E. Riviere, R. Guillot, S. Delprat, R. Mattana, P. Seneor, P. Ohresser, F. Choueikani, E. Otero, F. Koprowiak, V. G. Chilkuri, N. Suaud, N. Guihery, A. Galtayries, F. Miserque, M. A. Arrio, P. Sainctavit and T. Mallah, Nat. Commun., 2016, 7, 13646.

38 C. Train, G. Rikken and M. Verdaguer, in Molecular Magnetic Materials: Concepts and Applications, ed. B. Sieklucka and D. Pinkowicz, Wiley - VCH Verlag GmbH \& Co. KGaA, 2016, ch. 11, pp. 301-322.

39 H. D. Flack, Helv. Chim. Acta, 2003, 86, 905-921.

40 B. L. Silver, Irreducible tensor methods : an introduction for chemists, Academic, New York, 1976.

41 E. Anderson, LAPACK Users's Guide, Society for Industrial and Applied Mathematics, Philadelphia, 2nd edn, 1995.
42 W. H. Press, B. P. Flannery, S. A. Teukolsky and W. T. Vetterling, Numerical recipes: the art of scientific computing, Cambridge University Press, Cambridge, 1992.

43 C. J. Milios, R. Inglis, A. Vinslava, R. Bagai, W. Wernsdorfer, S. Parsons, S. P. Perlepes, G. Christou and E. K. Brechin, J. Am. Chem. Soc., 2007, 129, 12505-12511.

44 R. Inglis, C. J. Milios, L. F. Jones, S. Piligkos and E. K. Brechin, Chem. Commun., 2012, 48, 181-190.

45 E. R. Davidson, J. Comput. Phys., 1975, 17, 87-94.

46 B. Liu, Numerical Algorithms in Chemistry: Algebraic Method, Lawrence Berkeley Laboratory, University of California, California, 1978, pp. 49-53.

47 S. Piligkos, E. Bill, D. Collison, E. J. L. McInnes, G. A. Timco, H. Weihe, R. E. P. Winpenny and F. Neese, J. Am. Chem. Soc., 2007, 129, 760-761.

48 S. Piligkos, H. Weihe, E. Bill, F. Neese, H. El Mkami, G. M. Smith, D. Collison, G. Rajaraman, G. A. Timco, R. E. P. Winpenny and E. J. L. McInnes, Chem. Eur. J., 2009, 15, 3152-3167.

49 E. K. Fields and S. Meyerson, Acc. Chem. Res., 1969, 2, 273278.

50 R. Inglis, J. Bendix, T. Brock-Nannestad, H. Weihe, E. K. Brechin and S. Piligkos, Chem. Sci., 2010, 1, 631636.

51 A. R. Tomsa, J. Martinez-Lillo, Y. L. Li, L. M. Chamoreau, K. Boubekeur, F. Farias, M. A. Novak, E. Cremades, E. Ruiz, A. Proust, M. Verdaguer and P. Gouzerh, Chem. Commun., 2010, 46, 5106-5108.

52 M. Soler, W. Wernsdorfer, Z. M. Sun, J. C. Huffman, D. N. Hendrickson and G. Christou, Chem. Commun., 2003, 2672-2673.

53 P. Parois, S. A. Moggach, J. Sanchez-Benitez, K. V. Kamenev, A. R. Lennie, J. E. Warren, E. K. Brechin, S. Parsons and M. Murrie, Chem. Commun., 2010, 46, 1881-1883.

54 H. Häkkinen, Nat. Chem., 2012, 4, 443.

55 E. Pensa, E. Cortés, G. Corthey, P. Carro, C. Vericat, M. H. Fonticelli, G. Benítez, A. A. Rubert and R. C. Salvarezza, Acc. Chem. Res., 2012, 45, 1183-1192.

56 M. Perfetti, F. Pineider, L. Poggini, E. Otero, M. Mannini, L. Sorace, C. Sangregorio, A. Cornia and R. Sessoli, Small, 2014, 10, 323-329.

57 I. Ashur, O. Schulz, C. L. McIntosh, I. Pinkas, R. Ros and A. K. Jones, Langmuir, 2012, 28, 5861-5871.

58 R. Bukasov and J. S. Shumaker-Parry, Nano Lett., 2007, 7, 1113-1118.

59 D. G. Castner, K. Hinds and D. W. Grainger, Langmuir, 1996, 12, 5083-5086.

60 T. M. Willey, A. L. Vance, C. Bostedt, T. van Buuren, R. W. Meulenberg, L. J. Terminello and C. S. Fadley, Langmuir, 2004, 20, 4939-4944.

61 J. Dreiser, A. M. Ako, C. Wäckerlin, J. Heidler, C. E. Anson, A. K. Powell, C. Piamonteze, F. Nolting, S. Rusponi and H. Brune, J. Phys. Chem. C, 2015, 119, 3550-3555.

62 M. Shima, K. Tsutsumi, A. Tanaka, H. Onodera and M. Tanemura, Surf. Interface Anal., 2018, 50, 1187-1190.

63 M. C. Biesinger, L. W. M. Lau, A. R. Gerson and R. S. C. Smart, Phys. Chem. Chem. Phys., 2012, 14, 2434-2442. 
64 S. A. Pizarro, P. Glatzel, H. Visser, J. H. Robblee, G. Christou, U. Bergmann and V. K. Yachandra, Phys. Chem. Chem. Phys., 2004, 6, 4864-4870.

65 S. Wang, L. Kong, H. Yang, Z. He, Z. Jiang, D. Li, S. Zeng, M. Niu, Y. Song and J. Dou, Inorg. Chem., 2011, 50, 27052707.

66 N. Kawamura, T. Yamamoto, H. Maruyama, I. Harada, M. Suzuki and T. Ishikawa, J. Synchrotron Radiat., 2001, 8, 410-412.

67 E. Sarigiannidou, F. Wilhelm, E. Monroy, R. M. Galera, E. Bellet-Amalric, A. Rogalev, J. Goulon, J. Cibert and H. Mariette, Phys. Rev. B: Condens. Matter Mater. Phys., 2006, 74 .

68 G. L. Nealon, B. Donnio, R. Greget, J.-P. Kappler, E. Terazzi and J.-L. Gallani, Nanoscale, 2012, 4, 5244-5258.

69 I. Carmeli, G. Leitus, R. Naaman, S. Reich and Z. Vager, J. Chem. Phys., 2003, 118, 10372-10375.

70 P. Crespo, R. Litrán, T. C. Rojas, M. Multigner, J. M. de la Fuente, J. C. Sánchez-López, M. A. García, A. Hernando,
S. Penadés and A. Fernández, Phys. Rev. Lett., 2004, 93, 087204.

71 S. Trudel, Gold Bull., 2011, 44, 3-13.

72 R. Singh, J. Magn. Magn. Mater., 2013, 346, 58-73.

73 F. Tassinari, D. R. Jayarathna, N. Kantor-Uriel, K. L. Davis, V. Varade, C. Achim and R. Naaman, Adv. Mater., 2018, 30, 1706423.

74 H. Al-Bustami, G. Koplovitz, D. Primc, S. Yochelis, E. Capua, D. Porath, R. Naaman and Y. Paltiel, Small, 2018, 14, 1801249.

75 J. S. Garitaonandia, M. Insausti, E. Goikolea, M. Suzuki, J. D. Cashion, N. Kawamura, H. Ohsawa, I. Gil de Muro, K. Suzuki, F. Plazaola and T. Rojo, Nano Lett., 2008, 8, 661667.

76 J. Dreiser, G. E. Pacchioni, F. Donati, L. Gragnaniello, A. Cavallin, K. S. Pedersen, J. Bendix, B. Delley, M. Pivetta, S. Rusponi and H. Brune, ACS Nano, 2016, 10, 2887-2892. 